\title{
APPRECIATION OF TRIAXIALITY INFLUENCE IN PLASTIC DEFORMATION ACCOMPANYING DUCTILE RUPTURE
}

\author{
COSERU (TULUCA) Ancuta-Ioana \\ Ph.D. student, Faculty of Engineering/Department Mechanical Engineering, Mechatronics, \\ "Vasile Alecsandri." University of Bacau, Romania, coseru.anca@gmail.com \\ ZICHIL Valentin \\ professor, Faculty of Engineering/Department Mechanical Engineering, Mechatronics, \\ "Vasile Alecsandri." University of Bacau, Romania, valentinz@ub.ro \\ LUPASCU Stefan \\ Ph.D. student, Faculty of Engineering/Department Mechanical Engineering, Mechatronics, \\ "Vasile Alecsandri." University of Bacau, Romania, stefan.lupascu@yahoo.com
}

\begin{abstract}
In this paper, the authors propose a studying method for the deformation that appears before crack of ductile materials using the Lode parameter determined by the numerical calculation applied on simple models, verified in previous studies. In order to highlight the influence of the Lode parameter, the tests were performed at simple but also at compound tests. The necessity of these studies lies in the fact that the acknowledged models (the use of the integral J, the critical stress intensity factor $K_{c}$ or the CPCD method) do not fully explain the phenomenon of deformation before breaking the elasto-plastic materials. The tests were imagined under the form of sets. Each set of tests was performed on smooth specimens and on specimens with a notch radius of 0.5, 2, 4 and 10 $\mathrm{mm}$. Also, each set of tests was performed for pure tensile and combined tensile-torque test.
\end{abstract}

Key words: Lode's angle, Lode's parameter, triaxiality, tensile-torque test

\section{Introduction}

In 1961, Wells proposed a new approach for the cases where the extensive plastic flow at the stage before the crack extension invalidates the application of the concept developed by the stress intensity factor Kc. Thus, Wells proposed a post-crack displacement (PCD) taking into account a critical peak crack displacement (CPCD). Thus, the $\mathrm{J}_{\mathrm{c}}, \mathrm{K}_{\mathrm{c}}$ and CPCD criteria have been differentially used depending on the material: the first two applied mainly to elastic materials (fragile breaking), the last one being applied to the elasto-plastic materials (ductile fracture) [1]. Although the expression of the stress intensity factor K, used for the calculation of the critical value $\mathrm{K}_{\mathrm{c}}$ includes the influence of the geometry of the specimen without dissociating the triaxiality state of stresses and deformations, the critical intensity factor $\mathrm{K}_{\mathrm{c}}$ is only sometimes independent of the geometry of the specimen [1]. Since the analytical expressions of the $J_{c}, K_{c}$ and CPCD methods cannot fully explain all the phenomenon of the initiation or cessation of the crack, a series of empirical attempts have been developed to explain the complexity of the phenomenon under certain conditions and on certain types of specimens.

\section{Theoretical aspects}

Recent researches [2] has shown that it is possible to express each tension state through the main stresses. According to the models developed for plasticity and cracking, it is preferable to use other analysis factors such as the triaxiality and the Lode's factor. The authors propose a method of studying the deformation accompanying the cracking of ductile materials using the numerical calculation applied on simple models, verified in previous studies. In order to highlight the influence of stress triaxiality, the tests were carried out at simple and complex loads.

Stress triaxiality $\beta$ is defined as the ratio between the hydrostatic stress and the equivalent stress [3]:

$$
\beta=\frac{\sigma_{m}}{\sigma_{e q}, V M}
$$


where $\sigma_{e q, V M}$ is the equivalent von Mises stress expressed by:

$\sigma_{e q, V M}=\frac{\sqrt{2}}{2} \sqrt{\left(\sigma_{1}-\sigma_{2}\right)^{2}+\left(\sigma_{2}-\sigma_{3}\right)^{2}+\left(\sigma_{3}-\sigma_{1}\right)^{2}}$

and $\sigma_{m}$ is the hydrostatic stress:

$$
\sigma_{m}=\frac{\sigma_{1}+\sigma_{2}+\sigma_{3}}{3}=\frac{I_{1}}{3}
$$

Stress triaxiality is not constant in the nearest notch, the maximum value is determined behind the crack. Critical effective stress triaxiality is defined as the average value from the stress triaxiality distribution on the effective length [3].

$$
\beta_{e f, c}=\frac{1}{X_{e f, c}} \cdot \int_{0}^{X_{e f, c}} \beta(x) d x
$$

Other researches $[4 ; 5]$ have shown that the ductile fracture is the result of the accumulation of plastic strain and the damage depends both of the Lode's angle and hydrostatic pressure. The model used in analytical calculations is represented by a function of the three tensors of the invariant stress:

$\mathrm{J} 1$ - shows the sensitivity of hydrostatic pressure;

$\mathrm{J} 2$ - shows the equivalent von Mises stress;

J3 - shows the Lode's angle.

Xue - Wierzbicki criterion suppose that the material is isotope and bears von Mises plasticity criterion, also that the failure is characterized by a deterioration factor formally expressed as (5):

$$
\sigma_{e q, V M}=w(D) \sigma_{M}
$$

where: $\sigma_{e q, V M}$ : equivalent von Mises stress;

$$
w(D) \text { : the deterioration factor, } \mathrm{D}=[0,1] \text {. }
$$

Lode's angle is represented in a deviator plane, as the angle between the O'P and O'A directions, where $\mathrm{P}$ is the stress state and $\mathrm{A}$ is the condition of pure shear (Figure 1) [2].

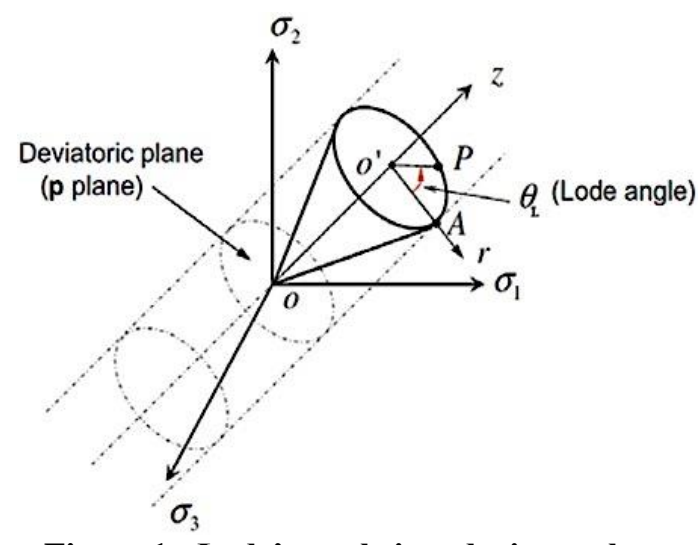

Figure 1: Lode's angle in a deviator plane

Lode's parameter $\xi$ is defined as the ratio between the cube of the third invariant and the equivalent stress. Lode's parameter is also referred in the literature as the equivalent angle of Lode, with a significant role in the ductile rupture at low stress triaxiality values [6], as shown in Figure 2. 


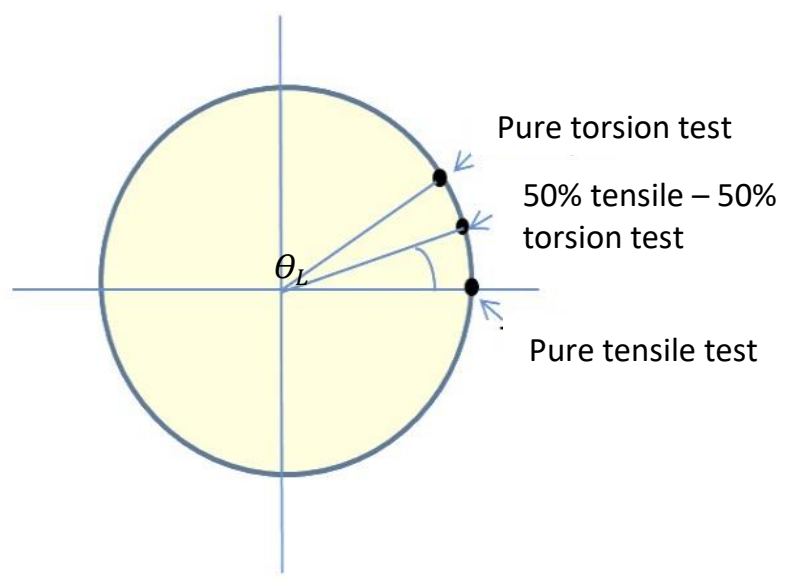

Figure 2: Lode's angle variation for different loads on smooth specimen

\section{Experimental procedure}

The chemical composition of the API 5L X65 steel from which the specimens were made is given as a percentage in Table 1 and the main mechanical properties are shown in Table 2 [7]:

Table 1: Chemical composition of API 5L X65 steel

\begin{tabular}{|c|c|c|c|c|c|}
\hline $\mathbf{C}(\mathbf{m a x})[\%]$ & Mg (max) [\%] & Phosphate (max) [\%] & S (max) [\%] & H [\%] & Si (Max) [\%] \\
\hline 0,1 & 1,5 & 0,015 & 0,005 & $0,007 / 0,015$ & 0,35 \\
\hline
\end{tabular}

Table 2: The mechanical characteristics of API 5L X65 steel

\begin{tabular}{|c|c|c|}
\hline Young modulus E [GPa] & Elasticity limit [MPa] & Breaking limit [MPa] \\
\hline 210 & 510 & 650 \\
\hline
\end{tabular}

The tests were performed on the smooth specimen and upon notch specimens with a radius of the notch ranging from $0.5 \mathrm{~mm}$ to $10 \mathrm{~mm}$. For numerical calculation Abaqus 6.10 program was used. The geometry of the specimens considered for this study is shown in Figures 3 and 4.

The finite element analysis calculations were based on 3D models.

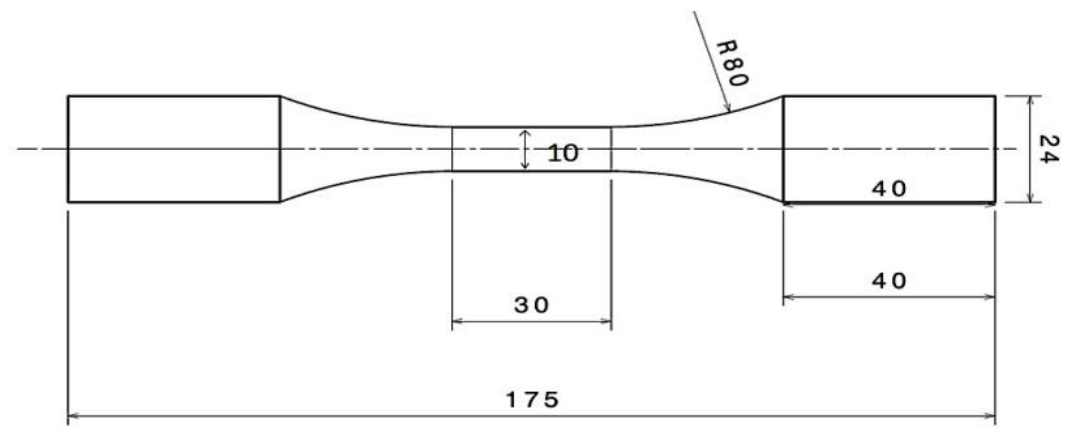

Figure 3: The geometry of the smooth specimen 

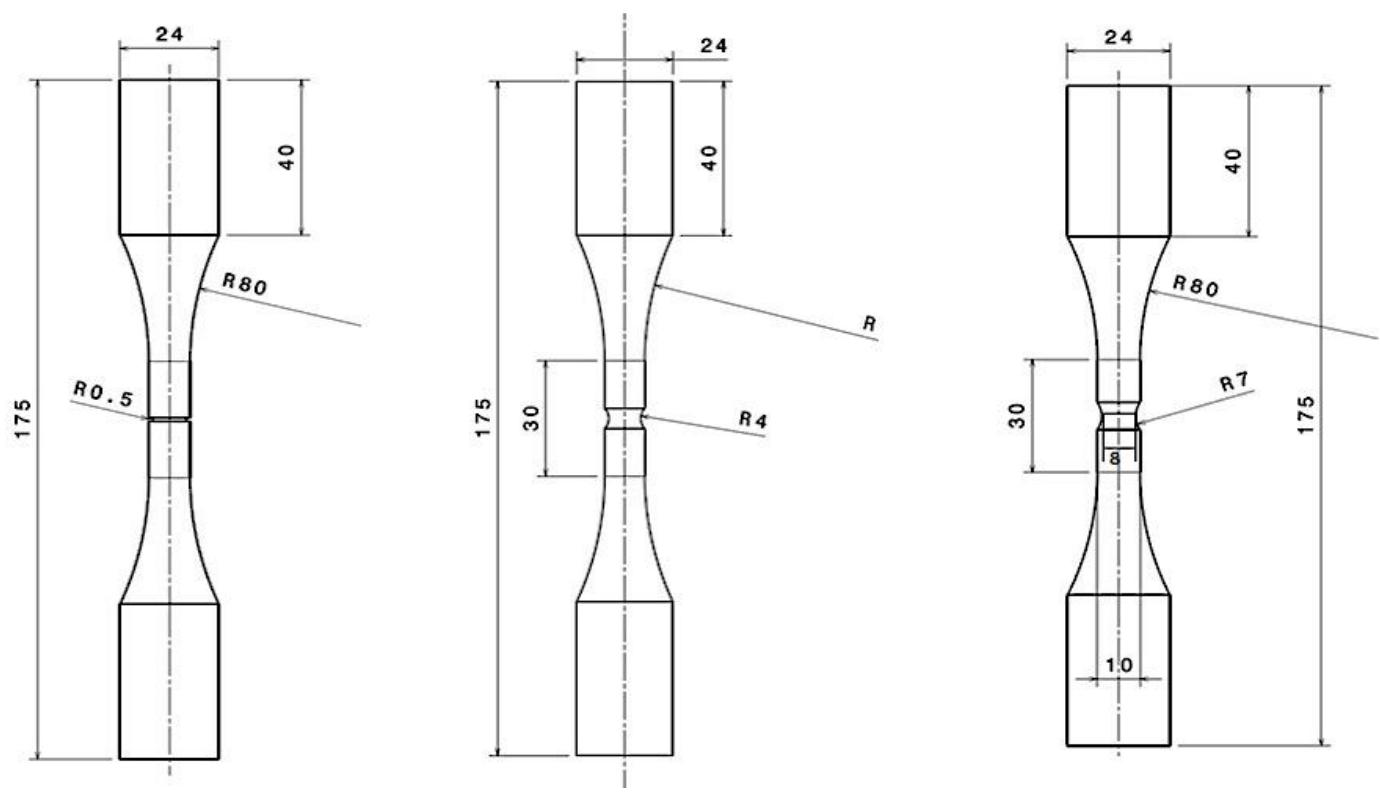

Figure 4: The geometry of the notched specimen, different radius of the notch

Tests were performed on smooth specimens and upon notch specimens. The tensile test was performed applying a force range between $10 \mathrm{kN}$ and $25 \mathrm{kN}$. The specimens have an initial diameter of 10 $\mathrm{mm}$, axially symmetrical, with an $8-\mathrm{mm}$ notch, a $30 \mathrm{~mm}$ long working part and an $80 \mathrm{~mm}$ radius of the countersink.

\section{Results}

The test was imagined as sets. Each set of tests was performed on smooth specimens and on notch specimens with a radius of the notch as follows: $0.5 ; 2 ; 4$ and $10 \mathrm{~mm}$. Also, each set of tests was performed for pure tensile test and compound tensile-torsion test.

Taking into account the nominal stress value:

$$
\sigma_{N}=\frac{F}{\pi \cdot b^{2}}
$$

in order to determine the stress triaxiality, three loading situations were performed, with reference to the stress flow of the material $\left(\sigma_{y}\right)$ :

$$
\frac{\sigma_{y}}{\sigma_{N}}<1, \frac{\sigma_{y}}{\sigma_{N}}=1 \text { and } \frac{\sigma_{y}}{\sigma_{N}}>1
$$

The values obtained for stress triaxiality in all the situations above described are shown in Tables 3 - 6. The related graphical representation is shown in Figures 5 - 8.

Table 3: Stress triaxiality values for pure tensile test

\begin{tabular}{|c|c|c|c|}
\hline & $\boldsymbol{\sigma}_{\mathbf{y}} / \boldsymbol{\sigma}_{\mathbf{N}}<\mathbf{1}$ & $\boldsymbol{\sigma}_{\mathbf{y}} / \boldsymbol{\sigma}_{\mathbf{N}}=\mathbf{1}$ & $\boldsymbol{\sigma}_{\mathbf{y}} / \boldsymbol{\sigma}_{\mathbf{N}}>\mathbf{1}$ \\
\hline $\mathbf{r}[\mathbf{m m}]$ & \multicolumn{3}{|c|}{$\boldsymbol{\beta}_{\text {ef }}$} \\
\hline $\mathbf{0 . 5}$ & 0.83585 & 0.94024 & 0.99876 \\
\hline $\mathbf{2}$ & 0.60434 & 0.65014 & 0.67029 \\
\hline $\mathbf{4}$ & 0.51103 & 0.54621 & 0.56838 \\
\hline $\mathbf{1 0}$ & 0.4219 & 0.42826 & 0.45013 \\
\hline
\end{tabular}


ACTA UIVERSITATIS CIBINIENSIS - TECHNICAL SERIES

$100 \%$ tensile test

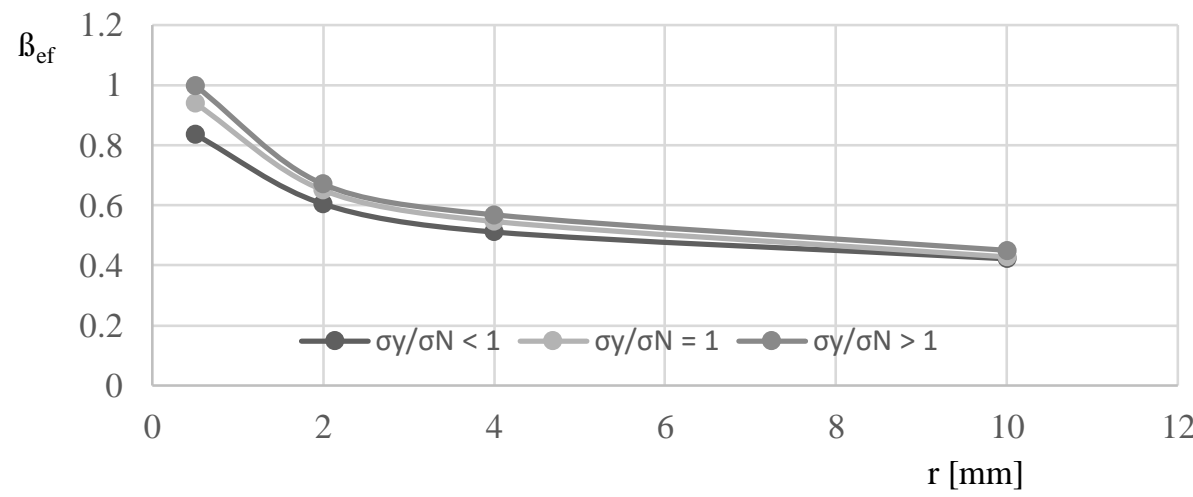

Figure 5: Stress triaxiality variation for pure tensile test

Table 4: Stress triaxiality values for compound $75 \%$ tensile $-25 \%$ torsion test

\begin{tabular}{|c|c|c|c|}
\hline & $\boldsymbol{\sigma}_{\mathbf{y}} / \boldsymbol{\sigma}_{\mathbf{N}}<\mathbf{1}$ & $\boldsymbol{\sigma}_{\mathbf{y}} / \boldsymbol{\sigma}_{\mathbf{N}}=\mathbf{1}$ & $\boldsymbol{\sigma}_{\mathbf{y}} / \boldsymbol{\sigma}_{\mathbf{N}}>\mathbf{1}$ \\
\hline $\mathbf{r}[\mathbf{m m}]$ & \multicolumn{3}{|c|}{$\boldsymbol{\beta}_{\text {ef }}$} \\
\hline $\mathbf{0 . 5}$ & 0.61609 & 0.61897 & 0.63546 \\
\hline $\mathbf{2}$ & 0.53268 & 0.53998 & 0.56219 \\
\hline $\mathbf{4}$ & 0.44609 & 0.4516 & 0.47658 \\
\hline $\mathbf{1 0}$ & 0.41801 & 0.44178 & 0.46382 \\
\hline
\end{tabular}

$75 \%$ tensile $-25 \%$ torsion test

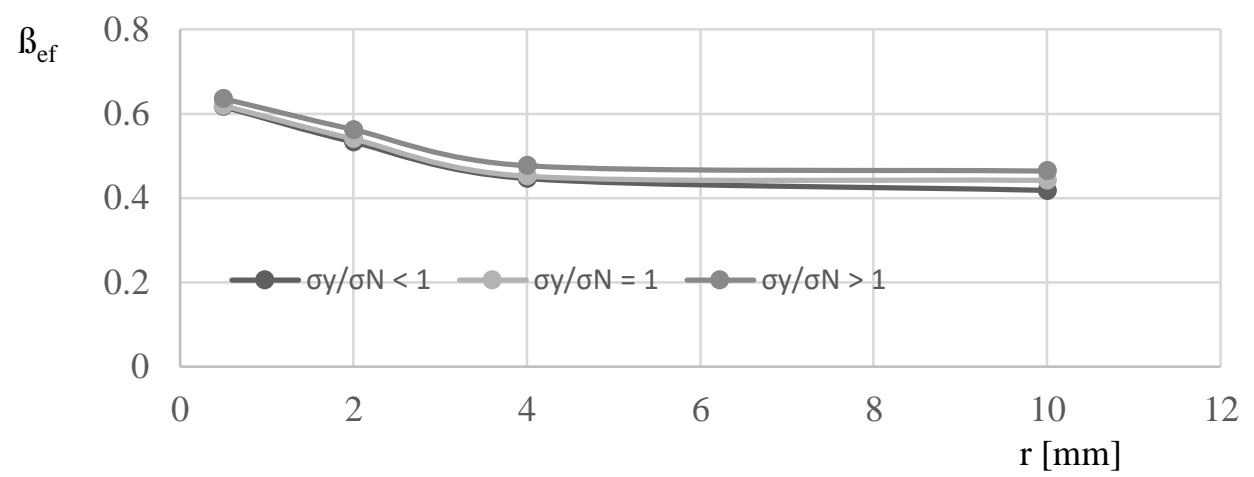

Figure 6: Stress triaxiality variation for $\mathbf{7 5 \%}$ tensile $-25 \%$ torsion test

Table 5: Stress triaxiality values for compound $50 \%$ tensile $-\mathbf{5 0 \%}$ torsion test

\begin{tabular}{|c|c|c|c|}
\hline & $\boldsymbol{\sigma}_{\mathbf{y}} / \mathbf{\sigma}_{\mathbf{N}}<\mathbf{1}$ & $\boldsymbol{\sigma}_{\mathbf{y}} / \boldsymbol{\sigma}_{\mathbf{N}}=\mathbf{1}$ & $\boldsymbol{\sigma}_{\mathbf{y}} / \boldsymbol{\sigma}_{\mathbf{N}}>\mathbf{1}$ \\
\hline $\mathbf{r}[\mathbf{m m}]$ & \multicolumn{3}{|c|}{$\boldsymbol{\beta}_{\text {ef }}$} \\
\hline $\mathbf{0 . 5}$ & 0.34887 & 0.35072 & 0.35614 \\
\hline $\mathbf{2}$ & 0.3163 & 0.31804 & 0.32027 \\
\hline $\mathbf{4}$ & 0.2851 & 0.29275 & 0.30144 \\
\hline $\mathbf{1 0}$ & 0.26104 & 0.27141 & 0.29001 \\
\hline
\end{tabular}




\section{ACTA UIVERSITATIS CIBINIENSIS - TECHNICAL SERIES}

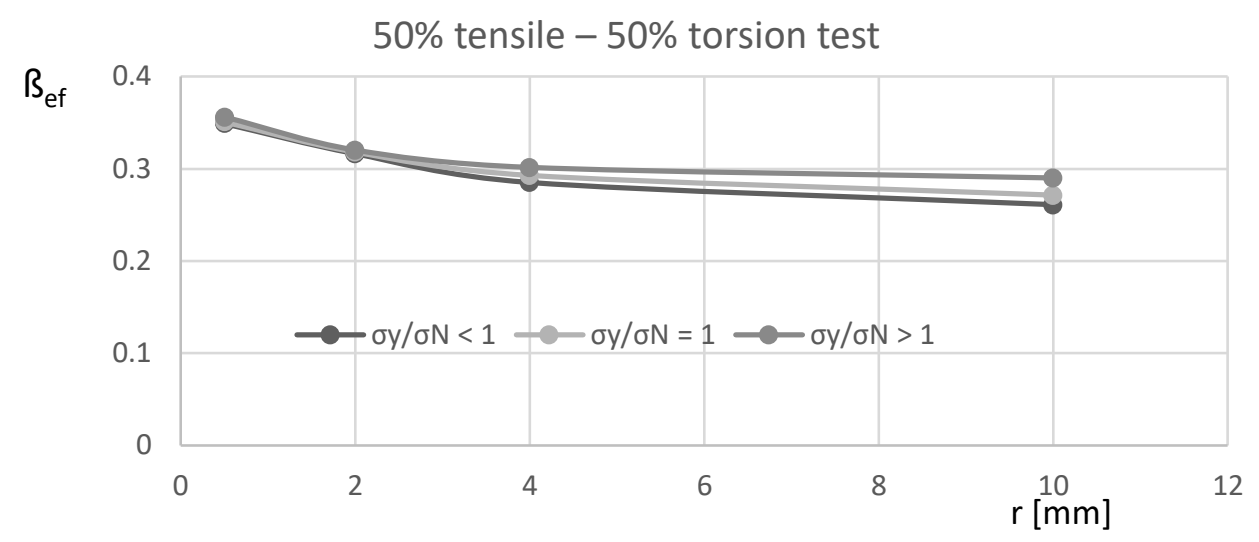

Figure 7: Stress triaxiality variation for $\mathbf{5 0 \%}$ tensile $-\mathbf{5 0 \%}$ torsion test

Table 6: Stress triaxiality values for compound $25 \%$ tensile $-75 \%$ torsion test

\begin{tabular}{|c|c|c|c|}
\hline & $\boldsymbol{\sigma}_{\mathbf{y}} / \boldsymbol{\sigma}_{\mathbf{N}}<\mathbf{1}$ & $\boldsymbol{\sigma}_{\mathbf{y}} / \boldsymbol{\sigma}_{\mathbf{N}}=\mathbf{1}$ & $\boldsymbol{\sigma}_{\mathbf{y}} / \boldsymbol{\sigma}_{\mathbf{N}}>\mathbf{1}$ \\
\hline $\mathbf{r}[\mathbf{m m}]$ & & $\boldsymbol{\beta}_{\text {ef }}$ \\
\hline $\mathbf{0 . 5}$ & 0.12858 & 0.15278 & 0.17355 \\
\hline $\mathbf{2}$ & 0.12624 & 0.14819 & 0.15502 \\
\hline $\mathbf{4}$ & 0.11065 & 0.13468 & 0.14679 \\
\hline $\mathbf{1 0}$ & 0.10801 & 0.11775 & 0.12894 \\
\hline
\end{tabular}

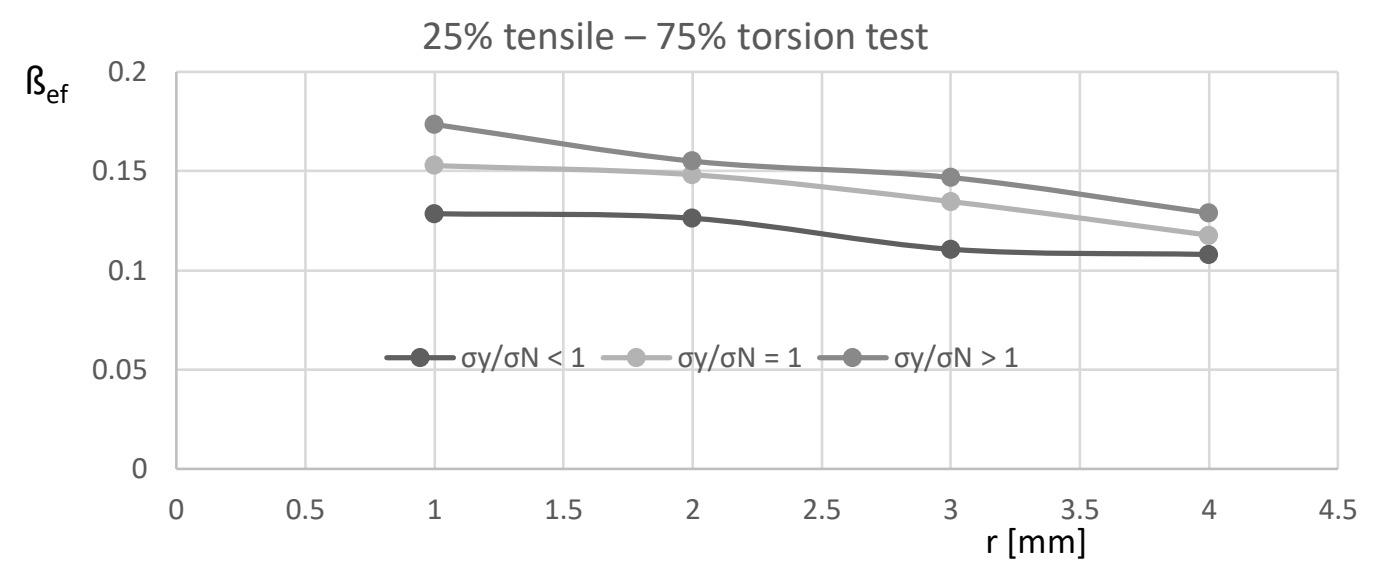

Figure 8: Stress triaxiality variation for $25 \%$ tensile $-75 \%$ torsion test

On the other hand, stress triaxiality depends on the geometry of the specimen (according to equation (1)). At a small notch radius, a high value for stress triaxiality is obtained from analytical calculations, and vice versa in case of a large notch radius, a small value.

For pure torsion test, stress triaxiality is almost equal to zero, the phenomenon may be explained through the hydrostatic pressure which is almost zero. For pure tensile test, stress triaxiality is equal to 1.

\section{Conclusions}

Breakage of ductile materials is closely related to the dependence of hydrostatic stress and therefore stress triaxiality is dependent on hydrostatic stress. The highest value of stress triaxiality was obtained at pure tensile test, on studied specimens.

In the authors opinion, the deformation phenomenon that occurs at the breakage of ductile materials can be more accurate explained using parallel to dedicated methods, such as Jc, Kc, CPCD, experiments developed on specific specimens. By those experiments is possible to rate the value of the stress triaxiality, which varies in a large range, depending on the specimen geometry, as is shown in Figure 
9.

The authors believe that the stress triaxiality along with the Lode' parameter should be regarded as an important factor in deformation process of ductile materials.

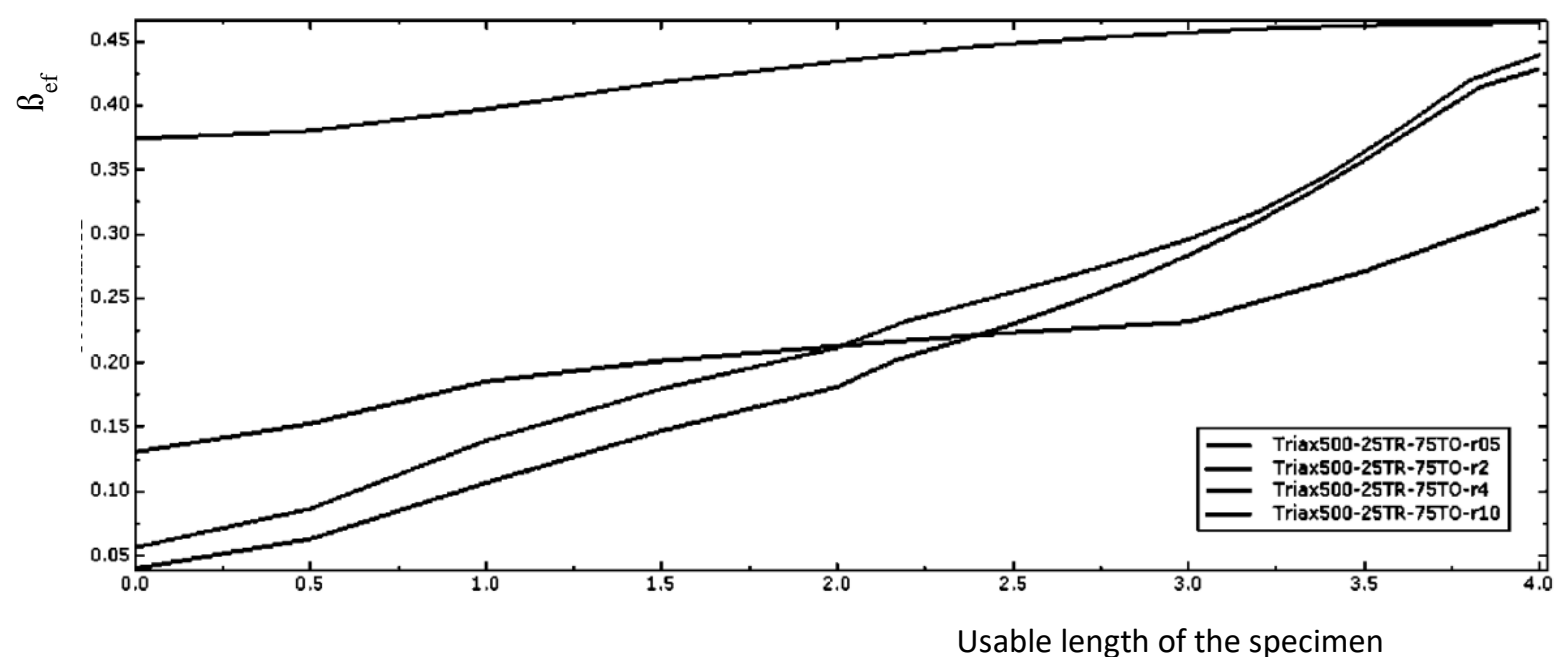

Figure 9: Stress triaxiality variation with the length of the specimen at a $25 \%$ tensile $-75 \%$ torsion test, $\sigma_{\mathrm{N}}=500 \mathrm{MPa}$

\section{References}

1. Cioclov, Dragos, Mecanica ruperii materialelor, Editura Academiei Republicii Socialiste România, București, România, (1977).

2. Mirone, G., Keshavarz, A., Ghajar, R., Triaxiality Factor and Lode Angle Effects on Failure of X-100 Steel Considering Plastic Anisotropy, Advanced Design and Manufacturing Technology, Vol.5, No.4, pp. 27 -31, (2012).

3. Zichil, V., Coseru A., Nedeff F., Tomozei C., IOP Conf. Series: Materials Science and Engineering 012066 doi:10.1088/1757-899X/200/1/012066, Baia Mare, Romania, (2017).

4. Xue L., Ductile fracture modeling - theory, experimental investigation and numerical verification, Ph.D. thesis, Massachusetts Institute of Technology, (2007).

5. Xue L., Stress based fracture envelope for damage plastic solids, Engineering Fracture Mechanics, vol.76, pp. 419-438, (2009).

6. Danas, K., Ponte Castaned, P., Influence of the Lode parameter and the stress triaxiality on the failure of elastoplastic porous materials, International Journal of Solids and Structures, doi: 10.1016/j.ijsolstr.2012.02.006 (2012).

7. Pluvinage, G., General approaches of pipeline defect assessment, Safety Reliability and Risks associated with water, oil and Gas pipelines, Edited by Pluvinage, G. and Elwany, M. , Springer, (2007). 